\title{
O nudge na prática: algumas aplicações do paternalismo libertário às políticas públicas
}

The nudge in practice: some applications of libertarian paternalism to public policies

\section{Thomas Ramiro}

thomas.ramiro@gmail.com

Universidade Federal do ABC (UFABC)

\section{Ramon Garcia Fernandez}

ramon.garcia.fernandez@gmail.com

Universidade Federal do ABC (UFABC)

Resumo: Este artigo tem como objetivo abordar e problematizar o paternalismo libertário nos termos de suas características e exemplos recorrentes. Esta visão política, aparentemente contraditória, pois alia aspectos do paternalismo sem limitar a liberdade do indivíduo, surgiu, por sua vez, de acordo com os estudos dos chamados nudges e da arquitetura de escolha, traçados no âmbito da economia comportamental. Dessa maneira, faz-se importante abordar também esta vertente econômica, uma vez que, crítica ao modelo axiomático de indivíduo racional, presente na abordagem econômica neoclássica, reforçou os estudos referentes à racionalidade limitada, algo que também possui consequências no campo de políticas públicas, principalmente perante a formulação e resultados esperados de uma política. Sendo assim, é necessário abordar e investigar estas novas visões e ferramentas, mas também problematizá-las, de modo a indicar seu devido alcance e suas possíveis falhas.

Palavras-chave: Economia Comportamental; Paternalismo Libertário; Políticas Públicas

Abstract: This article aims at addressing and discussing libertarian paternalism in terms of its characteristics and recurrent examples. This political approach, which might at first seem contradictory since it argues paternalist principles while maintaining individuals' freedom, has emerged in accordance with studies of the concept of nudges and the architecture of choice, explored in the scope of behavioral economics. Along these lines, it is also important to address this economical ideology, seeing that it is critical of the axiomatic model of the rational individual that's present in the neoclassical economical approach. Along with that, it also has reinforced limited rationality studies, influencing the public policies field, especially in terms of policy making and expected outcomes. Therefore, it is necessary to address and investigate these new views and tools, but also questions them, in order to point out their actual reach and possible flaws.

Keywords: Behavioral Economics; Libertarian Paternalism; Public Policies

\section{INTRODUÇÃO}

Um dos pressupostos encontrados tanto na formulação de políticas públicas, quanto no pensamento econômico atualmente padrão, de viés neoclássico, é o de indivíduo racional, aspecto no qual se espera um comportamento estratégico individual em meios para se atingir fins ótimos. 
Se, em termos econômicos, objetiva-se, geralmente ${ }^{1}$, um fim maximizador, na área de políticas públicas, o aspecto do indivíduo racional encontra-se ligado à formulação das mesmas, assim como os resultados prováveis, tendo em vista o comportamento esperado da população de acordo com aquela política.

Ocorre, porém, que esta não é a realidade de fato. Assim como Herbert Simon apontou para a racionalidade limitada do indivíduo e dos próprios policy makers, dentro da economia temos, ao se realizar uma análise da formulação teórica do campo, que a adoção do homem racional encontrase ligada ao momento em que a teoria neoclássica foi formada, onde se buscou estabelecer este axioma de modo a formular teorias econômicas mais abrangentes, com poder preditivo maior, algo que se remetia à tentativa de aproximar a economia das ciências naturais nos termos do método científico, como apontam Angner e Loewenstein (2007). Até este momento, então, a economia encontrava-se com preceitos psicológicos; Bernoulli, por exemplo, havia traçado o conceito de utilidade, o qual correspondia a um valor subjetivo de um ganho, o que, portanto, tinha implicações introspectivas, algo que, na interpretação neoclássica, formulada posteriormente, não se compunha de acordo com um método científico.

É necessário dizer, ainda, que esta simplificação da análise econômica se deu sob a influência dos estudos de Von Neumann e Morgenstern, como aponta Heukelom (2007), onde este conceito de utilidade, no aspecto da economia, foi reduzido a termos monetários e a maximização dos mesmos, algo aprofundado por Samuelson e outros autores que estabeleceram os critérios axiomáticos perante o comportamento de decisão do indivíduo, que agora seria composto de uma escala de preferências, as quais, por sua vez, seriam consistentes, invariáveis e independentes. Angner e Loewenstein (2007) apontam, ainda, que a formação destas preferências não era mais estudada, sendo este mais um dos aspectos que a economia abandonou, pois também se remetia à abordagem introspectiva.

Apesar de ter sofrido várias críticas e abordagens distintas por correntes heterodoxas, este critério de racionalidade dentro da economia neoclássica se manteve, algo que somente veio a ser colocado em cheque, de maneira mais incisiva, após a década de 70. Como apontam Angner e Loewenstein (2007), estabeleceu-se a chamada revolução cognitiva, onde se houve avanços significativos na área de análise comportamental da decisão e que indicou erros sistemáticos e até mesmo replicáveis no processo de decisão, algo que comprometia, inclusive através de experimentos, a racionalidade axiomática estabelecida. A passagem para a área econômica foi

\footnotetext{
1 "Geralmente", pois, segundo Angner e Loewenstein (2007), dentro da economia neoclássica há uma série de suposições auxiliares, muitas vezes não usadas, acerca de questões de preferência, que, muitas vezes, não correspondem a uma lógica puramente maximizadora.
} 
realizada, por exemplo, por Daniel Kahneman e Amos Tversky, estudiosos da área da psicologia, que tiveram sucesso em levar seus achados de heurísticas e vieses, assim como sua "teoria do prospecto" (ou perspectiva) ao campo econômico, retomando, inclusive, aspectos que se remetiam à utilidade subjetiva de Bernoulli.

Estabeleceu-se, assim, a chamada área da economia comportamental, a qual será analisada brevemente na primeira seção deste trabalho, onde se buscará traçar suas principais ideias e estudos, que inspiraram o chamado paternalismo libertário. Esta abordagem política, por sua vez, será abordada nas seções seguintes, havendo, na segunda seção, uma abordagem de modo a caracterizála para depois, na terceira seção, traçar exemplos de algumas políticas tomadas dentro do seu viés. Faz-se importante também, de modo a estabelecer um debate mais acentuado, a quarta seção, onde se objetiva traçar algumas ponderações e críticas do paternalismo libertário e suas políticas, sem o objetivo de se esgotar o debate, mas de forma a concluir o objetivo investigativo deste trabalho em abordar estas novas ferramentas para se tratar de políticas públicas.

\section{ECONOMIA COMPORTAMENTAL}

É importante ressaltar, inicialmente, o aspecto de que a economia comportamental não se compõe como uma área totalmente nova; como citado, durante a história do pensamento econômico, diversos autores aproximaram a economia dos estudos psicológicos para além de sua origem, como Herbert Simon, George Katona e até mesmo Keynes. O que logrou maior sucesso na atualidade, porém, foi o avanço promovido por Daniel Kahneman, Amos Tversky e outros estudiosos, os quais exploraram novos métodos e até mesmo aplicações para a realidade, traçando estudos que contestavam as teorias vigentes do comportamento econômico e também da utilidade, a qual se encontrava reduzida. Kahneman e Tversky (1984) entendiam, ainda, que a teoria da utilidade vigente era tomada não somente como um modelo descritivo, mas também normativo, no sentido em que os indivíduos seguiam os princípios axiomáticos ou então tinham a propensão de fazê-lo, algo que vieram a contestar durante seus estudos.

Kahneman e Tversky apontam, principalmente, para os chamados "atalhos cognitivos", que muitas vezes, acabam resultando em erros sistemáticos, apontados no comportamento de decisão do indivíduo. Para isso, primeiramente traçam um sistema dual perante decisões na mente humana: composta pelo "Sistema 1" (ou automático) e "Sistema 2" (ou reflexivo), que, como indicados pelos nomes, correspondem a um mais rápido e instintivo e um outro mais lento e racional, consecutivamente. Os erros sistemáticos estariam dentro do que chamam de "heurísticas e vieses" (KAHNEMAN; TVERSKY, 1974) e se remeteriam ao primeiro sistema, que, ao elaborar "atalhos 
mentais" para chegar a acertos rápidos perante escolhas, pode cometer erros, sendo estes, de acordo com os estudos destes autores, replicáveis, primeiramente, em laboratório, mas também na vida real, podendo haver, portanto, consequências.

Estas "heurísticas e vieses" tem importância de análise perante o processo de decisão do indivíduo, uma vez que demonstram, através desses erros sistemáticos, uma discrepância com os princípios axiomáticos do homem racional, já que, muitas vezes, são ligadas com concepções próprias dos indivíduos, desviantes, por exemplo, de aspectos de estatísticas e outros meios de cálculos racionais que seriam tomados perante certas decisões. Kahneman e Tversky (1974) apontam para os seguintes fenômenos: representatividade, disponibilidade e a ancoragem, todos se compondo como processos envolvidos durante uma tomada de decisão, que podem ter o objetivo de auxiliar em respostas mais rápidas, porém, como indicado pelos experimentos dos mesmos, chegam a levar a erros.

Dentro da chamada representatividade, seria observado o estabelecimento de relações entre objetos e grupos, ou então de fatos e consequências que, muitas vezes, podem não levar em conta a probabilidade real de eventos ou de um tamanho amostral, havendo ainda, efeitos relativos a contextos e experiência dos indivíduos. Este último ponto encontra-se presente, também, dentro do viés da disponibilidade, onde o indivíduo recorre a ocorrências e casos perante questões incertas, algo, inclusive, que pode levar a um grande otimismo ou pessimismo de acordo com pensamento de casos bem sucedidos ou mal sucedidos. Por estes aspectos, nota-se que o contexto em que as decisões são apresentadas deve ser levado em conta, como ainda indicado por Kahneman e Tversky (1974), algo também presente dentro do fenômeno da ancoragem, onde um ponto inicial, como um número aleatório, pode levar a estimativas e resultados em torno do mesmo.

Fica mais claro este aspecto do contexto, quando estes mesmos autores traçam a chamada teoria da perspectiva, utilizando-se, também, do efeito enquadramento (KAHNEMAN; TVERSKY, 1984), onde criticam a teoria padrão da utilidade e indicam fatores como a aversão à perda, e a propensão ao risco, mas em medidas diferentes, o que leva a domínios e curvas distintos em ambientes tomados como ganhos ou perdas. 


\section{Imagem 1 - Representação Gráfica da Teoria da Perspectiva de Kahneman e Tversky}

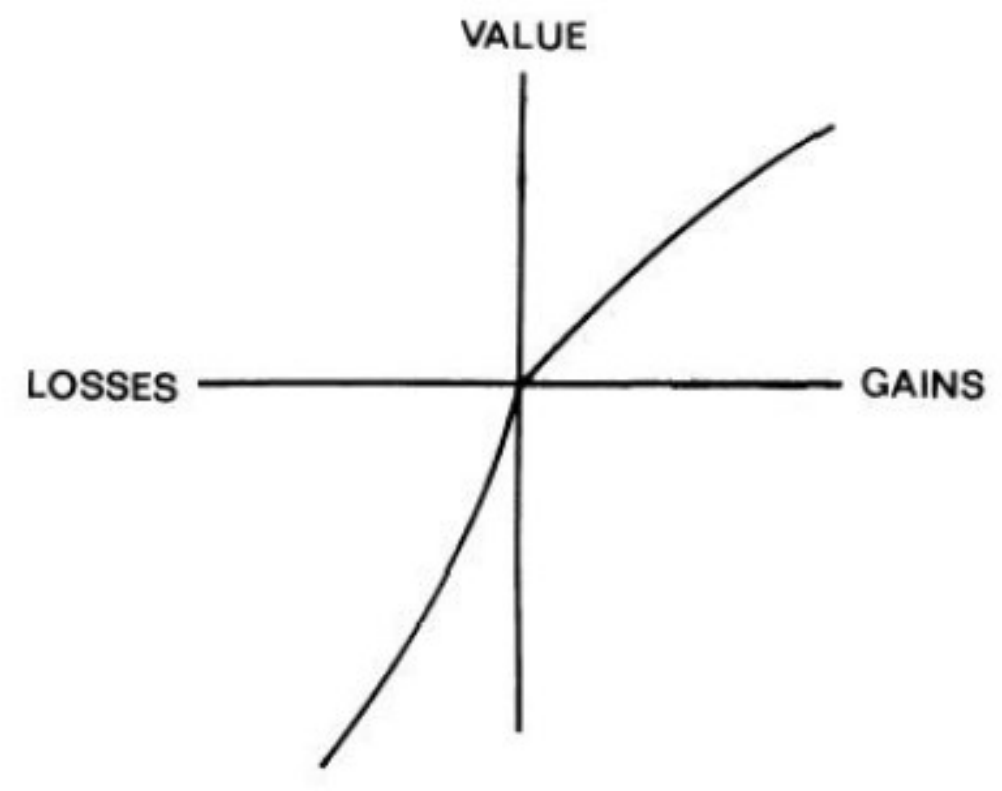

Fonte: Heukelom (2007, p. 14)

Dessa forma, estabelece-se que há uma sensibilidade perante a forma como questões e decisões são apresentadas, o que é indicado pela tentativa de manter um status quo quando uma situação é apresentada em forma de perda (aversão ao risco), mas uma propensão ao risco quando se é apresentada uma mesma situação em forma de ganho, o que indicaria, por exemplo, a transgressão de preferências consistentes (preferir sempre A ao invés de B).

Grande parte desses estudos de Kahneman e Tversky se baseou em experimentos de laboratório, envolvendo grupos em referência a decisões que refletiam situações no cotidiano, como apostas e outras situações de incertezas. Este ponto é algo em comum que a economia comportamental teve, em seu início, com a economia experimental, baseando-se em experimentos de laboratório que colocariam à prova suas teorias, havendo, no caso dos achados da economia comportamental, discrepâncias com a teoria econômica padrão e o comportamento racional. Com o tempo, outros estudiosos se envolveram com estes achados e resolveram aplicar métodos distintos, como indicam Angner e Loewenstein (2007), buscando experimentos ainda mais ligados com a realidade e, enfim, estudos de campo, os quais validavam os achados do laboratório.

Heukelom (2007) aponta, ainda, que um importante patrocinador da pesquisa em economia comportamental é a "Russell Sage Foundations" (RSF), mantenedora de um centro de estudos, onde autores como Richard Thaler, Cass Sunstein, Colin Camerer, Matthew Rabin e George 
Loewenstein, se inspiraram nas análises de Kahneman e Tversky, mas acabaram por seguir caminhos distintos, inclusive em aspectos metodológicos. É importante abordar este aspecto de acordo com o que se objetiva neste trabalho, uma vez que haveria dois principais grupos, ainda segundo Heukelom, sendo um deles mais presente perante as questões de políticas públicas.

O primeiro, no qual se encontram os próprios Kahneman e Tversky, mas também Thaler e Sunstein, por exemplo, pensa em uma abordagem que diferencia os termos normativos e descritivos do processo de escolha, ou seja, como a teoria afirma, como os indivíduos deveriam se comportar e como eles se comportam de fato, adicionando um outro elemento, o prescritivo, onde se pensa em como políticas podem ser estabelecidas de modo a fazer com que os indivíduos se comportem de acordo com a teoria normativa. O segundo grupo, onde se encontram Camerer e Rabin, por exemplo, já pensa somente em uma distinção positiva-normativa da economia, recebendo os achados psicológicos, mas entendendo que eles devem ser usados apenas para criar teorias positivas com bom poder preditivo, mantendo uma certa distância entre os métodos da psicologia e da economia.

\section{NUDGE, ARQUITETURA DE ESCOLHA E PATERNALISMO LIBERTÁRIO}

Tendo abordado os principais achados da economia comportamental e traçando a separação proposta por Heukelom (2007) em dois grupos, para fins de políticas públicas e indicando um maior viés de análise potencial para a economia comportamental em termos de políticas, o primeiro grupo estabeleceu estudos mais aprofundados, havendo, inclusive, focos de análise distintos, desde desenvolvimento, pobreza, meio-ambiente, saúde e outros. Uma abordagem em especial é a do "paternalismo libertário", traçado por Thaler e Sunstein (2003), pensada, inclusive, em torno de outro artefato desses autores: o nudge, que corresponde à parte normativa, mas também prescritiva e, principalmente, à extensão da economia para a área das políticas públicas.

O chamado nudge é abordado por Thaler e Sunstein (2008), em um livro de nome homônimo, onde estes autores pretendem analisar aspectos da tomada de decisão, mas também situações no cotidiano norte-americano onde haveria a necessidade de "empurrões" ou "cutucadas" (nudges) para determinadas escolhas atingirem um bem-estar, seja em caráter privado ou mesmo público. Diante disso, vão abordar áreas como a educação, saúde, meio-ambiente e dinheiro, citando também a questão do "paternalismo libertário", o qual será abordado adiante, levando em conta, também, o que chamam de "arquitetura de escolhas", a qual corresponderia ao mecanismo pelo qual um indivíduo, no papel de formulador de uma situação, como, por exemplo, um policy maker, recorre para elaborar um ambiente de escolhas. No caso do paternalismo libertário, essa arquitetura 
de escolhas deve ser pensada em um âmbito de se facilitar que os indivíduos e a sociedade atinjam seus objetivos em termos de bem-estar, se valendo, inclusive, dessas orientações em forma de nudges, mas também através de informações mais claras e que correspondam à capacidade de racionalidade limitada entendida pelos autores.

Além da colaboração desses novos termos para a elaboração de políticas públicas, Thaler e Sunstein (2008), se utilizam dos estudos de Kahneman e Tverksy acerca das "heurísticas e vieses", retomando a concepção dual de tomada de decisão (sistemas automático e reflexivo), assim como o viés da representatividade, disponibilidade e o efeito da ancoragem, mas também incluindo e abordando o otimismo, a confiança excessiva, outros aspectos do enquadramento e também um viés de "inércia" (status quo), o qual abordaria como os indivíduos se mantêm com algumas escolhas ruins, mesmo tendo consciência das mesmas. No caso, tanto o nudge, quanto a arquitetura de escolhas seriam mecanismos para serem adotados por entes públicos e privados para vencer os resultados tidos como ruins, provenientes das decisões embasadas nessas heurísticas e vieses, sem, ainda, comprometer as decisões tomadas de forma deliberada por outros indivíduos.

Thaler e Sunstein (2008), ainda abordam que o nudge deve ser mais presente perante decisões que possuem uma resposta "retardada", ou seja, escolhas que são "difíceis, raras e oferecem pouco feedback; e aquelas cuja relação entre escolha e experiência é ambígua" (THALER; SUNSTEIN, 2008, p. 82). O que se entende, portanto, é que as medidas relativas à arquitetura de escolhas e o nudge devem atender decisões onde os indivíduos podem cometer erros, sem saber onde erraram e sem a possibilidade para acumular a experiência devida para uma mesma decisão, como, por exemplo, investir, adquirir uma previdência ou comprar uma residência, que são escolhas que indivíduos, muitas vezes, apenas tomam uma vez, ainda mais levando em conta, em alguns casos, do viés do status quo, onde mesmo que haja a possibilidade do indivíduo mudar sua escolha, pode enfrentar uma inércia própria ou um caminho trabalhoso perante formulários, documentos e informações. Caberia, portanto, uma atuação estatal, inclusive de forma regulatória, perante essas questões.

Em um ambiente político, porém, onde se figuram como opostos paternalistas e liberais, como no caso da realidade norte-americana, os autores abordam o aspecto do "paternalismo libetário", citado, ainda por Thaler e Sunstein (2003), como um termo que não deve ser considerado um oxímoro. Estes autores entendem que muitos economistas se compõem como libertários, tendo uma visão, inclusive, anti-paternalista, até mesmo porque possuem a crença de que o indivíduo sempre (ou quase sempre) toma suas decisões de acordo com os seus objetivos. Como abordado acima, um dos princípios da economia comportamental é uma crítica a este pressuposto, uma vez que os indivíduos possuem diversos mecanismos que os fazem tomar decisões que nem sempre são 
as melhores para si ou para a vida em sociedade, de acordo com os erros sistemáticos, havendo uma necessidade, portanto, de levá-los a um caminho tomado como melhor. É nesse sentido que o paternalismo libertário é proposto, de modo a indicar este caminho, mas também preservar a liberdade do indivíduo, uma vez que não haveria coerção, segundo estes autores.

Dessa forma, inclusive, é que Thaler e Sunstein (2008) vão falar do paternalismo libertário como uma "verdadeira terceira via", algo que seria embasado na visão norte-americana nos termos da polarização entre democratas e republicanos quanto à adoção de medidas de regulação e também de intervenções que poderiam ou não reduzir a liberdade de indivíduos. O que estes autores vão argumentar, todavia, é que os nudges respeitam a liberdade individual, assim como, novamente, podem ser elaborados tanto por governos (dentro do paternalismo libertário) quanto por entes privados, podendo haver benefícios para ambos, assim como para a sociedade, nos termos dos ganhos dessas arquiteturas de escolhas, sendo também importante ressaltar este aspecto, pois se pode contestar o papel do governo ou do mercado perante a determinar quais escolhas seriam as mais indicadas.

Um dos principais argumentos de Thaler e Sunstein (2003) para a adoção do paternalismo libertário é de que o próprio paternalismo é inevitável, sendo isto evidente na hora do policy maker estabelecer a chamada escolha padrão (default), a qual seria um ponto de partida perante certas políticas, correspondente, ainda, à chamada arquitetura de escolhas. Em um exemplo célebre, relativo à doação de órgãos, estes e outros autores se valem do exemplo do ponto de partida default para indicar como a mudança perante uma opção entre doação de órgãos ativa ou passiva, assim como a formulação do questionário pode levar a maiores índices de doação de órgãos em um país, fato que pode auxiliar em um bem-estar maior perante a saúde pública da sociedade (THALER; SUNSTEIN, 2008).

Ademais à questão de doação de órgãos, esse fator de opção padrão pode influenciar, por exemplo, na questão de consumo e racionamento de energia, uma vez que, aliando-se à questão da informação e o tratamento da mesma, dentro do aspecto de regulação, inclusive, pode-se projetar uma política que teria como objetivo comparar o consumo médio de um indivíduo perante os outros de seu bairro ou vizinhança, indicando as informações relevantes para saber se o mesmo estaria acima ou abaixo da média de consumo, sendo que, no primeiro caso, isto poderia fazer com que houvesse certa redução do consumo, de acordo com a opção padrão de se racionar energia.

Thaler e Sunstein (2003) entendem, ainda, que os indivíduos atuam dessa maneira, seguindo opções padrões, mas também sendo sensíveis a efeitos como o enquadramento, de acordo com a incerteza que os mesmos enfrentam no dia-a-dia, ou até mesmo de acordo com a inércia, o que as fazem manterem o ponto inicial de escolha. Então seria importante estabelecer este ponto de 
partida, buscando, justamente, um ganho estabelecido, mas que respeite a liberdade do indivíduo de agir de maneira contrária, caso o mesmo queira. No caso do enquadramento, é notável que o mesmo vá atuar e existir de qualquer maneira, como no caso de gastos com o cartão de crédito nos EUA, como apontado por Akerlof e Shiller (2009), havendo a necessidade, portanto, de, ao menos, providenciar informação de um modo "correto" neste ambiente incerto.

Outra questão a ser debatida é que já existem políticas relativas ao paternalismo libertário em funcionamento em alguns países, como é o caso nos EUA. Segundo Thaler e Sunstein (2003), por exemplo, dentro da lei de emprego e trabalho, há aspectos relativos a manter o bem-estar de trabalhadores, de acordo com opções que os mesmos podem tomar sem o devido planejamento, assim como há a questão de proteção ao consumidor, que coloca um período de "esfriamento" para determinadas decisões, uma vez que alguns indivíduos podem tomar decisões no calor do momento, sendo influenciados por sentimentos, como no caso, por exemplo, da compra de produtos vendidos na porta de casa, ou até mesmo no caso da decisão de se divorciar.

A formulação dessas políticas, segundo estes autores, deve ser embasada, ainda, em uma relação de custo e benefício, sendo necessário observar o que é mais válido perante algumas intervenções, inclusive nos termos de definição de escolhas padrões, uma vez que deixar as coisas incertas pode levar a custos altos. Nesses termos, deve-se repensar a questão do receio de que entes governamentais realizem as determinadas escolhas, por mais que os próprios indivíduos dentro do corpo burocrático podem estar sujeitos a esses aspectos de racionalidade limitada (SUNSTEIN; THALER; JOLLS; 1998). O que se deve levar em conta são os ganhos potenciais advindos de políticas como as mencionadas acima, inclusive nos termos dos pequenos nudges, que possuem baixos custos e podem ter efeitos importantes (SUNSTEIN; THALER, 2008).

\section{ASPECTOS E EXEMPLOS DE POLÍTICAS PÚBLICAS}

\subsection{Saúde Pública - Doação de Orgãos}

A partir do momento em que se caracteriza o paternalismo libertário, se faz importante, também, traçar exemplos de modo a ilustrar de forma mais efetiva os seus aspectos. Sendo assim, é importante, por exemplo, abordar o caso da doação de órgãos, como já citado, o qual é um exemplo recorrente na literatura de economia comportamental e do paternalismo libertário. Além de ser abordados por autores como Thaler e Sunstein, é bem descrito por Kahneman:

Um artigo publicado em 2003 observou que o índice de doação de órgãos ficou perto de $100 \%$ na Áustria, mas foi de apenas $12 \%$ na Alemanha, ficou em $86 \%$ na Suécia, mas foi de apenas 4\% na Dinamarca. 
Essas enormes diferenças são um efeito de enquadramento, que é causado pelo formato da questão crítica. Os países com alto índice de doação tem um formulário do tipo 'optar pela exclusão', em que os indivíduos que não desejam doar devem ticar no campo apropriado. A menos que executem essa ação simples, eles são considerados doadores voluntários. Os países com baixo índice de doação não possuem formulário desse tipo: a pessoa deve ticar numa campo para se tornar um doador. Isso é tudo. A melhor forma isolada de prever se a pessoa irá ou não irá doar seus órgãos é a indicação da opção default que será adotada sem ter de ticar em um campo. (KAHNEMAN, 2012, p. 466 - 467)

Essa citação é importante para tratar de vários aspectos de uma política típica do paternalismo libertário: primeiramente se observa o ganho efetivo, no caso, traduzido pelo aumento do índice de doação de órgãos nos países que optam por este tipo de política, algo que tem implicações para a sociedade; também se nota a questão da manutenção da liberdade, pois os indivíduos que não desejam realizar a doação de órgãos podem simplesmente optar por sair do processo; a terceira implicação, também importante, é a questão da "opção default", que não somente indicaria essa tendência paternalista, mas que também pode ter outra implicação mais subjetiva: a de certo "constrangimento moral", provocada por uma influência social, como descrita por Sunstein (2013).

O artigo original que aborda o caso da doação de orgãos, de Johnson e Goldstein (2003), ainda aponta para os custos físicos, cognitivos e até mesmo emocionais envolvidos perante uma escolha padrão (default), indicando a importância da mesma, mas também o esforço que alguns indivíduos teriam de enfrentar para mudar seu status de doador. Por mais que isso implique que muitas pessoas podem se tornar doadores, mesmo desejando não ser, o que pode ser algo de caráter coercitivo, no caso do artigo publicado há a argumentação de que as pesquisas realizadas indicaram uma propensão da população norte-americana em ser favorável à doação, o que corresponderia a uma vontade pública, além do fato, já citado, dos indivíduos ainda serem livres para optarem em não serem doadores.

\subsection{Poupança e Finanças Pessoais}

Akerlof e Shiller (2009) apontam também outra área importante onde se pode aliar os estudos da economia comportamental, poucos gastos e ganhos significativos em termos públicos: a poupança. Os autores indicam, por exemplo, como se deu toda uma política com o objetivo de se estimular reservas na China, fato que acarretou em uma ampla participação da poupança no PIB. Este modelo, segundo Akerlof e Shiller, foi inspirado por Cingapura, país que implementou uma política de poupança análoga a um caso célebre da economia comportamental, o "Save More 
Tomorrow" de Benartzi e Thaler (2004), mas com escolhas promovidas pelo governo, o que acarretou em taxas de poupança de $50 \%$ por décadas no país.

O programa "Save More Tomorrow" (ou plano SMarT), no caso, foi planejado por estes autores dentro do contexto norte-americano, onde há de se escolher, de forma ativa, entre planos do chamado 401(k). Benartzi e Thaler (2004), porém, constataram que muitos funcionários de uma empresa tinham vontade de poupar, mas não sabiam, exatamente, a quantia ideal, sendo que também muitos falhavam em enxergar o impacto dessas decisões quanto ao futuro, nos termos de um bem-estar na aposentadoria, portanto falhando em escolher um desses planos de forma adequada. Sendo assim, estes autores desenharam um programa que colocava um grupo de empregados de uma empresa como signatários automáticos de um plano de poupança, onde os mesmos poderiam sair quando quisessem, sendo que ainda haveria um aumento automático da porcentagem do valor que seria poupado em decorrência dos aumentos salariais reais que viriam a ocorrer. O objetivo desse desenho de programa foi evitar, por exemplo, a procrastinação perante a vontade de se poupar, assim como a falta de planejamento no caso das mudanças perante o aumento salarial, mas ainda mantendo a liberdade do indivíduo quanto à decisão de se poupar.

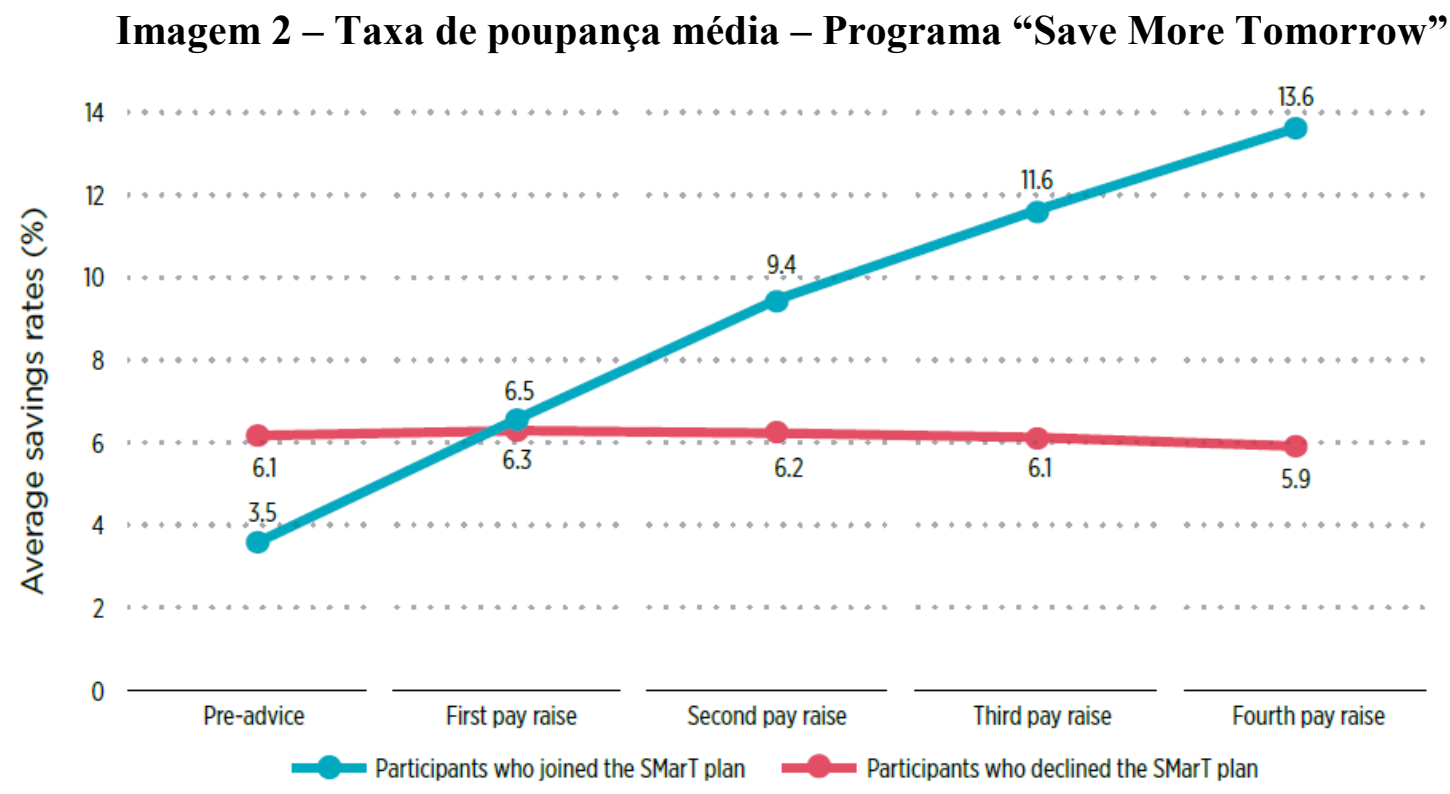

Fonte: World Bank (2015, p. 119)

Cabe falar que houve um aumento significativo no nível de poupança, de 3,5\% para 13,6\%, como indicado pela imagem 2, algo que reforça um desvio da teoria econômica tradicional, que, segundo Akerlof e Shiller (2009), apenas compreende que o ato de poupar se realiza através de um pensamento racional onde se pesa a possibilidade de gastar um dólar a mais agora ou poupá-lo para o amanhã, considerando os ganhos que você teria com essa ação e a busca por um equilíbrio. A 
teoria padrão também não leva em consideração, por exemplo, que as pessoas tem comportamentos não tão racionais e podem falhar em realizar esse cálculos e atingir este tal equilíbrio. Outro aspecto interessante é que o caso chinês indica que o estímulo externo também causa um efeito significativo, no caso citado, traduzido por propagandas nacionalistas que estimularam a poupança, algo que ocorre de forma contrária nos EUA, onde o consumo é mais estimulado, assim como, por exemplo, o uso do cartão de crédito, questões que caem, inclusive, no aspecto de enquadramento (framing).

\subsection{Iniciativas embasadas na promoção de informação}

Ainda sobre a questão de cartões de crédito, por exemplo, mas também em outras questões que envolvem preços complexos, falta de transparência e até mesmo incompreensibilidade de informações e taxas e, portanto, que tornam difíceis as decisões dos indivíduos, Thaler e Sunstein (2008) abordam uma possível vertente de regulamentação, baseada nos estudos da economia comportamental, chamada de RECAP (Registre, Examine e Compare Alternativas de Preço). Dentro dessa política, os autores entendem que o governo não regulamentaria os preços e serviços, mas sim as práticas de divulgação dos mesmos, objetivando informar os indivíduos da maneira mais clara possível, mas também de uma forma homologada, fazendo com que o formato seja algo generalizado, mesmo havendo diferenças entre as prestadoras de serviços. Essa iniciativa do RECAP salienta outro aspecto essencial de políticas no viés da economia comportamental, onde a informação e como a mesma é apresentada se tornam fundamentais para que os indivíduos consigam realizar suas decisões atingindo seu bem-estar, inclusive sendo menos vulneráveis aos erros derivados das heurísticas e vieses.

Thaler e Sunstein (2008) ainda apontam que uma arquitetura de escolhas efetiva deve trazer, para além de um ponto de partida embasado em escolhas padrões, o atendimento a esta demanda em se atingir um bem-estar (chamado de mapeamento, pelos autores). Deve-se, ainda, se esperar erros dos indivíduos, sendo necessário fornecer feedback para que os mesmos entendam onde erraram ou acertaram, de modo a possuir um aprendizado. Nesses últimos aspectos, a abordagem da informação e o tratamento da mesma, buscando se utilizar do efeito enquadramento de uma forma positiva (salientando ganhos, contextos positivos e ressaltando informações importantes), pode ser utilizada juntamente para se reforçar incentivos perante escolhas, medida já utilizada por entes públicos e privados para direcionar os indivíduos quanto a algumas decisões.

A questão da informação e como a mesma é apresentada e trabalhada na economia comportamental, ainda pode assumir outro papel: a de mensagens normativas, como apontada pelo artigo de um grupo de psicólogos de universidades norte-americanas. Segundo este estudo, uma 
mensagem normativa a qual detalha o consumo médio de energia de uma residência e do seu bairro, com o objetivo de se estabelecer um comparativo, pode levar a um aumento da conservação de energia (SCHULTZ et al., 2007), desde que acompanhada de outro tipo de mensagem, a qual também indicaria, no caso, se o consumo de energia era "aprovado" ou "desaprovado", traduzido por um emoticon feliz ou triste, consecutivamente. Os autores apontam que a diminuição do consumo de energia providenciaria um ganho financeiro privado, mesmo com implicações públicas, muitas vezes, mas que também pode levar a outros estudos análogos para diferentes áreas, o que acarretaria em ganhos de maior caráter público.

Ao passo em que este estudo indicaria uma área potencial para se atingir objetivos de ganhos em bem-estar social, através de algo embasado em informações, fornecimento de feedback, normas sociais e outras questões de caráter relativo à economia comportamental, um outro estudo, realizado por dois economistas americanos, indica que essas medidas relativas a nudges perante a conservação de energia pode não ser tão efetivo quanto o indicado. Costa e Kahn (2010), no contexto norte-americano, indicam que esses efeitos de providenciar informação e feedback embasados no consumo médio de energia do indivíduo e seus próximos é mais efetivo quando se trata de pessoas liberais ou com consciência ambiental, sendo que aqueles que tem propensão a serem mais conservadores, recusam-se a receber as informações ou são menos abertos às mesmas. Isso indicaria que o efeito deste nudge seria limitado e deve ser mais estudado.

\section{CRÍTICAS E PONDERAÇÕES}

Como trazido pelos exemplos acima, pode-se indicar que a perspectiva da economia comportamental, através das visões do paternalismo libertário e do nudge levam a novos escopos para a formulação e análise de políticas públicas. Todavia, esta visão deve ser problematizada e criticada, principalmente porque, uma vez que foi elaborada e desenvolvida majoritariamente nos países desenvolvidos, acaba por ter foco em preocupações distintas daquelas que seriam encontradas em países subdesenvolvidos e em desenvolvimento, que, muitas vezes, carecem de políticas públicas efetivas e eficientes para o bem-estar da sua população.

Nesse sentido, até mesmo os exemplos trazidos neste trabalho, relativos à doação de órgãos, aumento da poupança e a utilização e tratamento da informação de modo a orientar os indivíduos a tomarem melhores decisões, podem ser classificados como problemas "menores", que não correspondem a situações de carência maiores, nos termos, por exemplo, de distribuição de renda, implementação de saneamento básico, acesso à educação e outras necessidades que dizem respeito a 
maior parte dos países subdesenvolvidos e em desenvolvimento, que tem uma propensão maior à desigualdade. Nesse sentido, pode-se estabelecer uma relação com a tese de Selinger e Whyte (2012) de que os nudges não poderiam resolver problemas complexos, algo que estes autores avaliaram de acordo com o estudo de Adam Burgess, o qual analisa a situação da Grã-Bretanha, que colocou em prática uma unidade de nudge ("Behavioral Insight Team”) e buscou implementar, por exemplo, nudges em prol de estilos de vida mais saudáveis.

Burgess (2012) afirma que a realidade social é algo muito mais complexo, assim como as situações de resolução de certos problemas, citando que a abordagem da economia comportamental não leva questões como os "valores" do indivíduo, onde o "bem-estar" pode não corresponder à "felicidade". Selinger e Whyte (2012) abordam que o nudge somente pode ser encarado como uma forma emergente e emergencial de lei de regulação branda, tendo em vista que seus efeitos e abrangência são limitados, o que acarretaria em uma negativa acerca da proposição de Thaler e Sunstein (2008) de que o paternalismo libertário se componha como uma "terceira via", uma vez que as políticas de arquitetura de escolhas e do nudge correspondem mais a questões pontuais e não a uma forma que se estabeleceria, de fato, entre um intervencionismo estatal e normas dirigidas pelo mercado.

Por sua vez, Mongin e Cozic (2014), ao analisarem o próprio conceito do nudge e a perspectiva normativa, relativa ao paternalismo libertário, afirmam que os conceitos de "paternalismo" e "liberalismo" de Thaler e Sunstein são reduzidos de modo a aparentarem próximos, indicando, ainda, que a idéia de se orientar indivíduos para determinadas escolhas se compõe como uma manipulação, algo que entraria em conflito com a concepção de liberdade individual, não correspondente, somente, à liberdade de escolha defendida pelos autores do nudge. Isto pode, inclusive, estar relacionado ao argumento crítico, trazido pelos próprios Thaler e Sunstein (2008), da "slippery slope" ("ladeira escorregadia”), onde há um receio, por parte de alguns estudiosos e críticos, de que as orientações dentro do paternalismo libertário justifiquem intervenções cada vez mais fortes, o que também iria acarretar em prejuízo à liberdade dos indivíduos. Estes autores, porém, ressaltam a importância de analisar e até mesmo criticar suas idéias do paternalismo libertário e dos nudges a partir dos ganhos que podem acarretar e não de possíveis consequências distorcidas.

Mongin e Cozic (2014), por sua vez, também ressaltam a importância do trabalho de Thaler e Sunstein ao introduzir conceitos e análises que podem ajudar na questão de intervenções governamentais. Nesse viés, citam também a necessidade de se repensar os conceitos e explorá-los de forma mais eficiente, algo de essencial importância quando se trata de políticas públicas voltadas ao bem-estar da população. Assim, devem-se levar em conta os esforços de alguns estudiosos para 
uma abordagem da economia comportamental para o desenvolvimento e para a pobreza, como, por exemplo, Sendhil Mullainathan e Eldar Shafir que possuem estudos na área, que podem, inclusive, vir a tratar de questões mais ligadas aos interesses dos países subdesenvolvidos e em desenvolvimento.

Outro importante estudo nessa área, a qual pode colaborar com o desenvolvimento de políticas públicas mais efetivas, assim como o desenvolvimento de nudges que podem abordar questões mais complexas, é o relatório do Banco Mundial ( World Bank, 2015), intitulado "Mind, Society and Behavior", o qual tem como objetivo abordar perspectivas relativas ao desenvolvimento, levando em conta os estudos que indicam os elementos "irracionais" do comportamento humano. O relatório conta com exemplos, perspectivas, implicações e resultados, aliando teoria e prática e indicando a potencialidade e importância dessas novas abordagens, relativas à economia comportamental, perante $\mathrm{o}$ desenvolvimento de políticas para $\mathrm{o}$ desenvolvimento, algo que tem muito mais peso para solucionar problemas complexos e formular políticas públicas efetivas e eficientes.

\section{CONSIDERAÇÕES FINAIS}

Tendo se estabelecido como uma crítica à visão axiomática do indivíduo racional, encontrada na economia neoclássica, mas também na formulação de políticas públicas, a economia comportamental traçou seu caminho de experimentos a estudos de campo, estabelecendo implicações à teoria e à prática. Ao passo em que a "nova economia comportamental" atinge cerca de quatro décadas, ainda há muito que se desenvolver, mesmo em áreas que parecem consolidadas, como é o caso relativo às políticas públicas, paternalismo libertário, nudges e arquitetura de escolha.

Comprova-se isso através dos exemplos trazidos nesse trabalho, relativos à doação de órgãos e o programa "Save More Tomorrow", entre outros, que são exemplos típicos e célebres dos estudos e estudiosos da área, mas que podem ser facilmente criticados pelo seu caráter de "emergencial" e "pequeno". Ao passo em que os nudges se figuram, como Thaler e Sunstein (2008) indicam, como de pequeno custo e grandes resultados, esta afirmativa pode, à priori, não se comprovar, uma vez que há diversas críticas conforme o alcance dessas políticas, além do fato de não corresponderem, como citado, a políticas públicas que atendem os interesses de uma ampla parcela de indivíduos que residem em Estados que não possuem o determinado amparo. 
Em uma lógica de país desenvolvido, os nudges podem corresponder a situações de maiores alcances, como regulação, proteção ao consumidor, questões ambientais, produção de lixo e consumo de energia, que até chegam a serem demandas de indivíduos situados dentro de países subdesenvolvidos e em desenvolvimento, porém, deve-se pensar que há muitas áreas carentes, que necessitam de passos mais urgentes. Para esses fins, se faz necessário que se aumente os estudos sobre a área da economia comportamental pelos países menos privilegiados, buscando atingir seus interesses, assim como ressaltar a importância de iniciativas que já vislumbram combinar desenvolvimento e economia comportamental.

Nessa perspectiva, ainda se figura muito cedo em abordar o "paternalismo libertário" como uma "terceira via", se compondo o mesmo apenas como uma fonte para se repensar políticas, trazendo novas ferramentas de análise. Por mais, ainda, que acrescente uma perspectiva interessante de debate, tem seus efeitos limitados e mesmo sua definição é colocada em jogo por seus críticos, ainda mais quando se considera que sua elaboração também é relativa à dimensão norte-americana, onde as políticas do Estado tem uma preocupação muito maior em manter a liberdade individual através de ampliar escolhas, do que focar em amparar populações mais vulneráveis. Neste último ponto, porém, é onde políticas públicas e até mesmo perspectivas novas, como as trazidas pela economia comportamental, devem focar. 


\section{REFERÊNCIAS BIBLIOGRÁFICAS}

AKERLOF, George A.; SHILLER, Robert J. Animal Spirits. Princeton: Princeton University Press, 2009.

ANGNER, Erik; LOEWENSTEIN, George. Behavioral economics. 2007. Disponível em: $<$ http://papers.ssrn.com/sol3/papers.cfm?abstract_id=957148>, Acesso em 25 de setembro de 2013.

BENARTZI, Shlomo; THALER, Richard H. Save more tomorrow: Using behavioral economics to increase employee saving. Journal of Political Economics, v. 112, n. 1, pt. 2, 2004.

BURGESS, Adam. Nudging Healthy Lifestyles. European Journal of Risk Regulation, v.1, 2012.

COSTA, Dora L.; KAHN, Matthew E. Energy Conservation "Nudges" and Environmentalist Ideology. National Bureau of Economic Research Working Paper n. 15939, 2010.

HEUKELOM, Floris. Kahneman and Tversky and the Origin of Behavioral Economics, 2007. Disponível em: <http://papers.ssrn.com/sol3/papers.cfm?abstract_id=956887>, Acesso em 29 de junho de 2014.

JOLLS, Christine. SUNSTEIN, Cass. THALER, Richard. A Behavioral Approach to Law and Economics. Stanford Law Review, v. 50, 1998.

JOHNSON, Eric J.; GOLDSTEIN, Daniel. Do Defaults Save Lives? Science, v. 302, 2003.

MONGIN, Philippe; COZIC, Mikaël. Rethinking Nudges. Centre National de la Recherche Scientifique and HEC Paris, 2014.

SCHULTZ, Wesley P.; NOLAN, Jessica M.; CIALDINI, Robert B.; GOLDSTEIN, Noah J.; GRISKEVICIUS, Vladas. The Constructive, Destructive and Reconstructive Power of Social Norms. Psychological Science, v. 18, n. 5, 2007.

SELINGER, Evan; WHYTE, Kyle. Nudging Cannot Solve Complex Policy Problems. European Journal of Risk Regulation, v.1, 2012. Disponível em: <http://ssrn.com/abstract=1989466>, Acesso em 20 de outubro de 2014.

SUNSTEIN, Cass R. Nudges.Gov: Behavioral Economics and Regulation. 2013. Disponível em: < http://papers.ssrn.com/sol3/papers.cfm?abstract_id=2220022>, Acesso em 20 de novembro de 2014.

SUNSTEIN, Cass R.; THALER, Richard H. Libertarian Paternalism is not an oxymoron. Olin Law \& Economics Working Paper, n. 185, 2003.

SUNSTEIN, Cass R.; THALER, Richard H. Nudge: Improving decisions about Health, Wealth and Happiness. USA: Penguim Books, 2008.

TVERSKY, Amos; KAHNEMAN, Daniel. Judgment under Uncertainty: Heuristic and Biases. Science, New Series, v. 185, n. 4157, 1974.

TVERSKY, Amos; KAHNEMAN, Daniel. Choices, values and frames. American Psychologist, v. 34, 1984. 
WORLD BANK. Mind, Society and Behavior. World Development Report, 2015. 